\title{
10
}

\section{Local heritage and the problem with conservation}

\author{
Anna Karlström, University of Queensland, Brisbane, Australia
}

In a recently published book on South African heritage, Lynn Meskell suggests that nature protection and conservation predicts all discussions of the cultural past and that the overlapping discourses of natural and cultural heritages are dominated by the natural, reflected in contemporary biodiversity and conservation politics $(2012: 4,100)$. As these discourses are intertwined and difficult to separate from each other, I believe that current debates within cultural heritage conservation politics can also, and reversely, be used to enrich nature conservation discussions. Therefore, the focus for this article is not exactly a formally Protected Area regulated by law or guarded by nature conservationists, which according to the main objectives of this volume is the general scene for most of the contributions. Instead of exploring the interface between local groups and nature conservation, it explores connections between local groups and heritage conservation, ${ }^{1}$ directed by contemporary heritage discourse. ${ }^{2}$ This discourse includes traditional Western definitions of heritage that focus on material and monumental forms of tangible heritage, and conservationist ideal aiming at maintaining heritage as an unchanging monument to the past (Smith 2006:6, 29-34), a conservationist ideal that to a large extent is shared with contemporary nature conservation discourse. The relationship between local groups and heritage conservation illustrates the same kind of problem that can occur in the interface between local groups and nature conservation, where local groups represent 'other' views that sometimes challenge the conservationist ideal. I use my example from an area around Vientiane in Laos to highlight the different approaches to and meanings of conservation, i.e. that conservation not always is linked to permanence, but rather to change, and argue for the importance of local groups' involvement in heritage management projects, nature and/or culture. The examples I use here are part of my $\mathrm{PhD}$ research, conducted in Laos from 2001 to 2006, and based on long-term involvement and archaeological fieldwork including a mosaic of methodologies, such as excavations, interviews, participant observation and archive studies (Karlström 2009).

\footnotetext{
1 I want to mention something about how I use 'preservation' and 'conservation', since these concepts might appear interchangeably in the text. Within biology there is a preference to talk about nature conservation, but in the heritage field there is no clear, or general, distinction between heritage preservation and heritage conservation. However, the act of maintaining heritage, keeping it from the present for the future, is often called conservation in British English and preservation in American English. I mainly use conservation. When I refer to its technical meaning, i.e. the method or the profession of the conservator, it is always in connection to 'restoration'. In base form I use 'preserve' rather than 'conserve'.

2 Commonly referred to as Authorised Heritage Discourse (AHD), since Laurajane Smith coined the term in her book Uses of Heritage, which was published in 2006. I continuously refer to the 'contemporary heritage discourse(s)' throughout this article.
} 


\section{The problem with conservation}

There are primarily two perceptions, as I have argued elsewhere (Karlström 2009:193-196), that are decisive for the dominating conservationist ideal. The first is the presumption that a link with the past is necessary if we want to know who we are, to have an identity, and that this link provides certainties in an uncertain world. The other is the presumption that we need physical remains from the past to understand history. If we lose these remains, we will not be able to understand the past and we might as well lose our identities. The fear for this loss is, as I see it, the main reason for and motive behind the desire to preserve, which is a generally accepted starting point within contemporary heritage discourse. On the other hand, in a world where the Buddhist notion of material impermanence governs the perception of reality, conservation of material culture and heritage becomes a contradiction in terms (Karlström 2005:347-348). With these contradictions as a point of departure I argue, in this article, that culture heritage is something that we create because we, archaeologists and heritage managers, think that conservationist ideals are universal. To a large extent we also ignore not only local groups' views on what heritage is but also the fact that these views differ from the established views within the contemporary heritage discourse and that this fact results in that no universal ideals within heritage management can ever exist.

I consider the focus on material authenticity and the idea that heritage values are universal and should be preserved for the future, and preferably forever, as the main problems with conservation. However, is it possible to impose a conservationist ideal and frames of reference in contexts and worlds where non-conservationist ideals might prevail? Well, I don't think so. My argument for this answer lies within the following exploration of the concepts restoration and conservation, destruction and decay, and consumption, looting and loss, which all relate to and are dependent/ depend on conservationism: restoration and conservation are tools for keeping heritage from destructive influences. However, the meanings of the concepts differ, depending on the context. Restoration must not necessarily presuppose conservation. In turn, conservation can be a destructive force, and destruction might be needed for the conservation of certain heritage values. By illustrating the complexity between the two extremes conservation and impermanence, and the complexity between the different worlds in which they exist, I argue that we cannot continue to urge a universal frame of reference that recommends conservationism. This fundamentalist ideology of heritage conservation might even be dangerous (cf. Holtorf 2006). The different worlds I am talking about do not represent the dichotomies 'Western vs Eastern', or 'Christian vs Buddhist', or 'We vs the Other' straight off. There are obviously different worlds also in what seems a common world. Thus, the purpose of illustrating this complexity with my examples from Laos is not to show how a proper 'Buddhist heritage management' should be carried out. My purpose is rather to open up for other frames of reference than the one imposing conservation within heritage discourse, and to call for new heritage discourses to be created, including perceptions and values of local groups, might they be Buddhists or not.

A particular restoration-conservation debate, propelled by Viollet-le-Duc and Ruskin in mid nineteenth century Europe, is often brought up as the starting point for the ongoing debate about whether to restore/reconstruct or conserve heritage remains. Today, the term restoration refers to the act of returning something to its authentic or former state, but without adding new material (if additions are allowed they must be distinguishable from the original) and not necessarily aiming at unity in style. That is also how restoration is defined in the Venice Charter, which was approved in 1964. Whereas restoration aims at preserving and revealing historic and aesthetic values, based on respect for original materials, conservation is today dominated by scientific methodology, knowledge and values. Central to the contemporary field of conservation is a belief in scientific inquiry and that there is a fundamental need to preserve the integrity of the physical object. Regardless if reconstruction, restoration or conservation is argued for, the different approaches 
are all aiming at the same, namely to maintain authenticity and the feeling of originality. Wanting everything to be as close to the original as possible, for as long as possible, is a generally accepted starting point that prevails within contemporary heritage discourse and the present conservation ethics. Moreover, the final stage in the restoration and conservation processes is a complete thing or building. The consequence is often an unacquainted denial of a thing's life between construction and decay among contemporary heritage specialists. The practices, which occur in between, are explained as religious in nature, or supernatural (Byrne 1995; also this publication), or too subjective to be taken into account in modern scientific heritage practices. However, from a general Lao perspective it is what happens in between, concerning maintenance and restoration that is meaningful. But then, the significance and meaning of the term restoration is different from what was described above in connection to modern scientific heritage conservation practices.

Nevertheless, it is important to notice that the contemporary heritage discourse of course exists in Laos. At the two World Heritage sites, Vat Phou and Luang Prabang, this is officially the prevalent notion, and also among heritage managers working for the government in ministries and museums. In my first survey of Vientiane, I spent some time with officials working for different ministries, companies and organisations that were involved in urban planning, road construction, irrigation, mining etc. I interviewed, discussed and distributed questionnaires, through which I explored the heritage management at different levels. Most answers confirmed an awareness of existing international guidelines and legislations, and referred to the contents of national constitutions and laws concerning environmental impact assessments, which cover investigations of archaeological sites and cultural heritage. This awareness has significantly increased during the last decade, and laws and regulations become increasingly efficient. Still, at this level it is very much a question about priorities and money. Thus, in line with nationalistic ideologies about a glorious past propagated by the Lao government, only the monumental and spectacular remains from past times are prioritised, such as the World Heritage sites and, in Vientiane, for example That Luang, Vat Ho Phra Keo and Vat Sisaket. ${ }^{3}$ In other words, different worlds might as well be represented by different groups in society: local or non-local groups and groups located in the periphery or in the centre of economic and political power.

\section{Restoration-conservation}

Let us now move on to Vientiane and explore the concept of restoration. Often it is similar or equivalent to building a new monument, as an act of making merit. ${ }^{4}$ Restoration in this context means something radically different from what is implicit in modern scientific principles of conservation and preservation. It is rather a restoration of an idea of the prestige of the original, than of the physical form of the original.

\section{Phonesay - maintaining value through change}

In Ban Phonesay, one of the hundred villages of Vientiane city, there is a temple named Vat Phone Say Sethathirat. Commonly it is called just Vat Phonesay. After the capital of Lan Xang ${ }^{5}$ was moved from Luang Prabang to Vientiane almost 500 years ago, King Sethathirat had this temple built as a gift to his wife. This was also part of the procedure of stating power and royal kinship, which was marked by the building expansion in Vientiane during this period. The main temple construction, the sim, differs from most other in Vientiane. It is a low building, in traditional Lao

\footnotetext{
3 That Luang, Vat Ho Phra Keo and Vat Sisaket are historic temple sites in Vientiane that now are museums, and among the main tourist attractions in the city today.

4 In Buddhism, and particularly Theravada Buddhism, merit accumulates as a result of good deeds, acts or thoughts and is carried over to later in life or to a person's next birth.

5 Lan Xang was the first united Lao kingdom, established in 1356.
} 
style, and almost the only temple in its original shape from this period in Vientiane today, even though it has been restored now and again over the centuries. Close to the sim stands a stupa in disrepair (Figure 1). With my untrained eyes and limited knowledge, I characterised its condition as miserable when I first documented it in the initial phase of the survey. I soon understood that the heap of bricks and the Buddha statues, some complete and others at different stages of decay, were not at all neglected but rather looked after with the greatest care. Small pieces of gold leaf are every so often added to the deteriorated corpses of the Buddha statues in an act of meritmaking. Minor repairs as well as more extensive construction works are continuously carried out to maintain the stupa and the statues, activities carried out by villagers and monks and important for the everyday use of and religious practice at the temple (interviews with villagers and monks in Ban Phonesay, February 2002). It is also, through this repeated restoration process, that the prestige, or spiritual value, of the object is maintained.

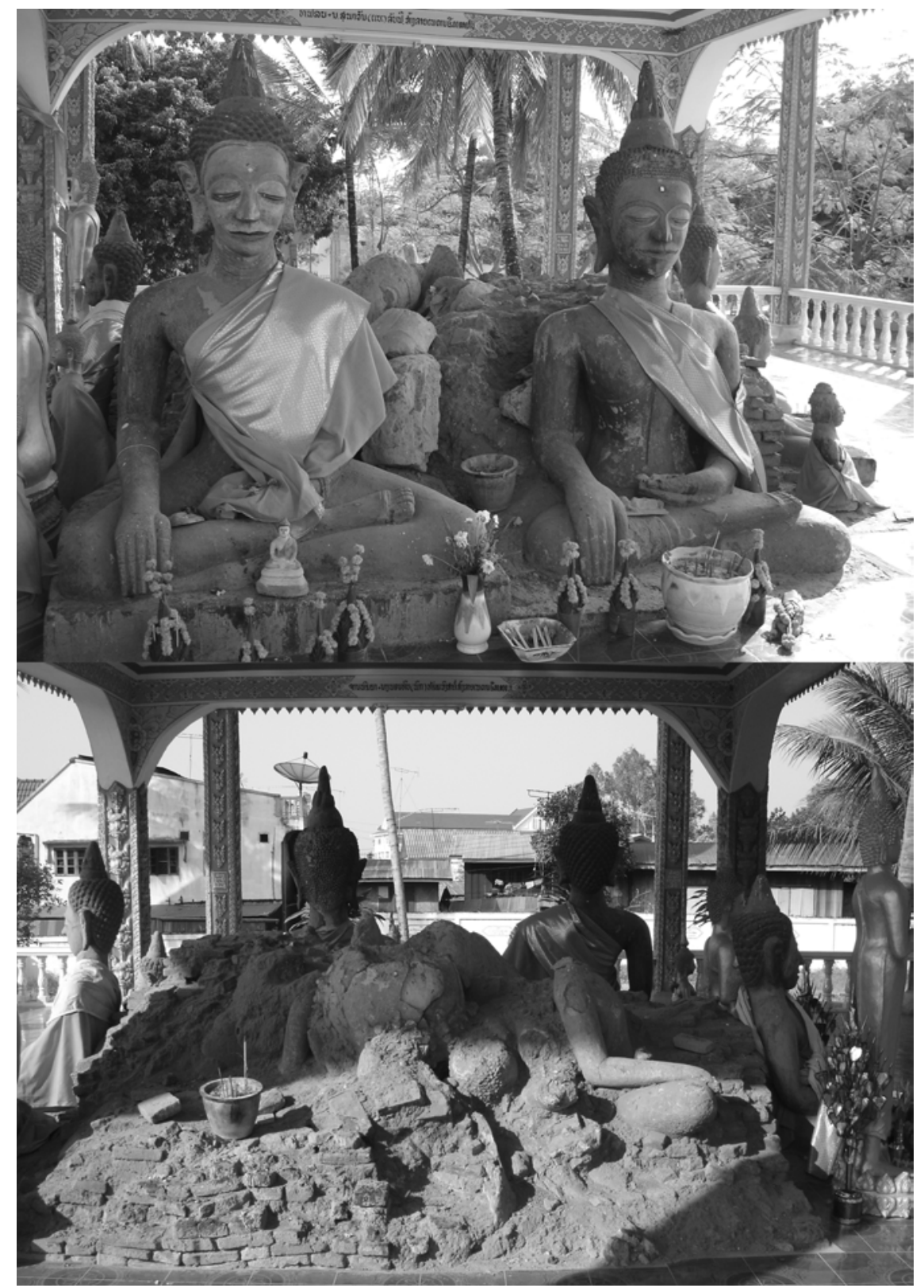

Figure 1. Buddha statues being restored at Vat Phonesay, front and back of the old stupa.

Source: Photo Anna Karlström. 
It is important to clarify here, that the reality in Laos is not a strictly doctrinal Buddhism, but rather a mix of animism and Buddhism (see Holt 2009 for a more detailed exploration about how Buddhism is related to Lao conceptions of spirits). Within this popular Buddhism different sorts of objects, such as images, amulets and stupas, that serve as mediums for concentration, aim at bringing to mind the person of the Buddha and inspiring to find the right way. These representations are often referred to as 'reminders'. It is not the physical form and fabric of these reminders that are of importance, but rather that the Buddha's attainment is symbolised by them, and as such, they act as a 'field of merit' (Tambiah 1970:45). True for all these reminders are that they are attributed with power, or arepower (cf. Holbraad 2007:189-225). This clearly illustrates the merging of Buddhism and animism, as these obviously Buddhist objects (Buddha images, stupas and amulets) become animated with spiritual power through different kinds of animistic and magical sacralisation rituals. By empowering objects, they become storage places for the spiritual values. And it is the spiritual value that has to be maintained.

It is also important to note the concept of authenticity here, and its different meanings. In contemporary heritage discourse material authenticity is one of the foundations and ascribed objects that are true and in their original state. This concept of authenticity privileges mainly unchanged conditions and presupposes a linear time perception, where appreciation and value grow the closer we come to the original state. However, authenticity in popular Buddhism is more about to what extent the object is empowered. It is not dependent on age or the material's originality. Exploring religious practices and beliefs and the production and use of images in Thailand, Denis Byrne writes that it is more relevant to talk about authenticity established via performance in a Southeast Asian context than about material authenticity (Byrne 1993). In this way, new images are constantly produced and recreated and must establish their own identities, which give them authenticity. Referring back to what I mentioned above about 'reminders' acting as 'fields of merit', we see that the value of the objects at Vat Phonesay has nothing to do with their form and fabric. It is what they represent and to what extent the object is loaded with significance and power that is important. This is also an example of the different conception of authenticity, which is established here through performance (Karlström in press). The restoration of the ancient Buddha statues at Vat Phonesay is an act of adding and changing the objects' form and fabric and by doing so establishing authenticity and maintaining the place's heritage values.

\section{Ou Mong - maintaining value by building something new}

Now almost twelve years ago, one of the oldest temples in Vientiane, Vat Ou Mong, was totally demolished. The sim ('ordination hall'), with its interior walls covered with ancient murals, was wiped out because it was to be replaced with a new sim. This was done as an act of merit-making that would enhance the beauty and prestige of the temple compound, and the merits of people's lives (Potkin 2001; Karlström 2009:16). Construction workers had already started to build a new sim at the temple compound when the demolition of the old sim was completed. As the walls grew higher, inscriptions with donors' names and the amounts of contribution were added, and signs were put up on the temple yard telling the same. I cannot say exactly when the construction work started, but it lasted over several years. When I passed the temple six years ago it was not yet completed, earlier this year it was. Even after the installation ceremony, when a temple receives its formal authority, building activities often continue. Following the inherent meaning of the merit-making act, the completion of a temple is subordinate to the process of its construction, which also challenges the general idea within contemporary heritage discourse that the final stage in the restoration and conservation processes is a complete thing or building. A temple under construction offers (in this case, the villagers living near the temple) a chance to donate money or provide volunteer labour, which means making merit. Adding, removing and elaborating over time are necessary parts of 
the merit-making act. With this more or less institutionalised maintenance practice, one can argue that the notion of completion is not relevant in this context. It is the (more or less constant) act of restoration that is important, rather than the result of it, after its completion.

In popular Buddhism, merit-making and other practices involving materiality are superior to the notion of impermanence. Things are important and significant. Not as remains from past times, but rather as part of the religious belief and practice. The stupa and the Buddha statues at Vat Phonesay are not defined as historical documents, worthy of preservation because of their ancient origin and material authenticity. At Vat Ou Mong, we also see that the ancient sim was not regarded valuable because of its material qualities. The demolition of the old sim and the construction of a new one at Vat Ou Mong illustrate another form of restoration practice, slightly different from the maintenance of the stupa and Buddha statues at Vat Phonesay (Figure 2). A restoration practice that has to do with the 'pouring through' of spiritual values. Whereas the Vat Phonesay stupa and Buddha images are reminders and important as instruments through which the significance of Buddha's life reaches people in the present, the Vat Ou Mong sim is a shell or a container, a storage place for spiritual values. And whereas the Vat Phonesay reminders need constant restoration through the adding of things to them (such as the gold leaf) for the significance to be maintained, the destruction of the Vat Ou Mong sim is necessary for the significance and the spiritual values first to be liberated and then free to enter, or pour through, to the new shell, the new sim, which is a result of the villagers' wish to gain merit (pers.comm., villagers in Ban Ou Mong 2000). Building a new sim is the most meritorous of acts the villagers can ever carry out, and therefore the restoration of the Vat Ou Mong sim is important primarily as a part in the merit-making act. Despite these differences, the essential meaning of the restoration practice is here shared: restoration is present-oriented and implies that things are added and constantly change.

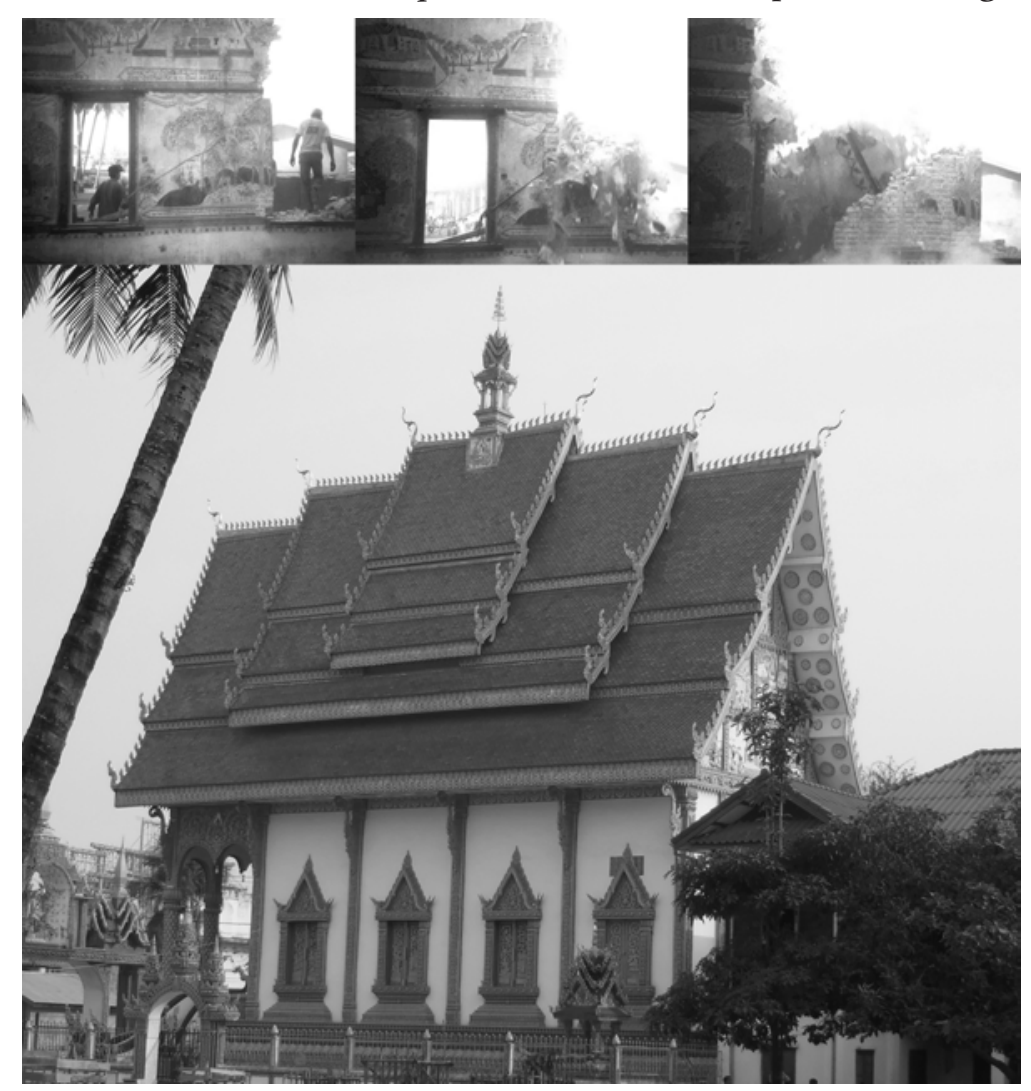

Figure 2. The old sim at Vat Ou Mong being demolished in December 2000 and the new sim completed. 
So, in contrast to the contemporary heritage discourse where restoration means returning a structure to its previous state and focusing on form and fabric and material authenticity, restoration means, in general in Lao society, returning the structure's prestige and spiritual values, by turning it to something new as a result of adding or changing its physical form and fabric. At Vat $\mathrm{Ou}$ Mong, the restoration means that the old building is replaced by a new building; the physical sim is turned to something new. By letting the spiritual values exit the old and enter the new, the prestige of the sim is returned. Similarly, the restoration of the ancient stupa and the Buddha statues at Vat Phonesay is an example of a process where the structures are constantly turned to something new as things are added, but by doing so, they are returned to their previous prestige. Returning prestige and spiritual values (not returning to original form and fabric) has to do with the act of merit-making and is an essential part of the religious practice and belief, i.e. what most people interviewed in the Vientiane survey considered their main heritage.

\section{Destruction and decay}

I will here continue to explore the concepts of destruction and decay and their relation to conservation, and I argue that they are mutually dependent. Although many of the problematic issues connected to the ideology of heritage conservationism have been discussed over the last century, destruction and decay are still most commonly regarded as threats to and in opposition to conservation. Recently, critical voices against the presumption that destruction and decay are threats to our cultural heritage have been heard and primarily triggered by conflicting values, wars and global terrorism (Meskell 2002; Holtorf 2006; Dolff-Bonekämper 2008; GonzálezRuibal 2008). ${ }^{6}$ In addition to these, there are others who focus on Asia, and bring up examples that well relativise destruction and conservation (cf. Byrne 1995; Johnson 2001; Lahiri 2001; Wijesuriya 2001). I want to illustrate here that the situation in such a seemingly uncontroversial context as Laos also prove to be reason enough for questioning that destruction is only a threat to cultural heritage, and that this in turn challenges the entire perspective of conservationism and its fundamental position within the contemporary heritage discourse.

According to the Buddhist notion of impermanence, decay is inevitable. Decay is a constant reminder of death and therefore, in accordance with the ideas of rebirth, essential for any celebration of life (Robinson and Johnson 1997:34-42; see Shanks and Tilley 1987:116 for similar ideas about materiality within archaeology). It is crucial for rebirth and finally enlightenment, the ultimate goal. Consequently, conservation as the opposite of decay and destruction becomes, in a strictly Buddhist perspective, a contradiction in terms. Even so, the notion of rebirth, and consequently the idea of decay as essential for rebirth, is valid also within popular Buddhism. In the case of Vat Ou Mong, the destruction of the sim was not a consequence of a strictly canonical Buddhist practice, but rather a result of the kind of popular Buddhism that is practiced there by the majority. The merging of Buddhism and animism is obvious if we look at the (Buddhist) sim as a storage place for spiritual values and power. These spiritual values and power in turn animate the sim through different kinds of (animist) sacralisation rituals and the destruction of the old sim is necessary for this power to pour through and animate the new sim. ${ }^{7}$

6 For example the Bamiyan Buddha statues, the Berlin Wall and the Twin Towers have been brought up as examples of how the destruction and loss of monuments and sites rather can create new meanings and produce heritage. Furthermore, Lynn Meskell speaks about the Bamiyan Buddhas as 'negative heritage', because for those who destroyed them, the Taliban, they represented a site of negative memory, and thus the act of destruction was a political statement (2002:561).

7 The distinction between what is Buddhist and what is animist might be a bit simplified here in this example, but it is just to show that they co-exist. In common and everyday religious practice it is impossible to distinguish Buddhism from animism, they are intertwined and operate within a total field (cf. Tambiah 1970:41). 
When it comes to another religious structure, the stupa, the situation is slightly different. At Vat Phonesay, for example, the ancient stupa is the instrument through which the significance of Buddha's life reaches people in the present, and is thus not only an impermanent container for spiritual values. Here, its decay is part of the restoration act, in which all stages in the circle of life are represented, and which ends with rebirth and the possibility of final extinction (pers. comm. villagers and monks in Ban Phonesay 2002). Destruction of the stupa at Vat Phonesay is not necessary, because its spiritual power needs not to pour through.

One of the other sites that were investigated within this project, Viengkham, provides yet another idea of how destruction and decay might be related to conservation within popular Buddhism. In connection with the excavations in 2004, there were discussions about moving the village's temple back to the place where the old temple site had been and where we at that time excavated. In contrast to the demolition of the sim at Vat Ou Mong, the two decayed temple structures at this old temple site could be left just as they were if a new temple was to be established there. Because, at that particular site, the two mounds had increasingly turned into animistic objects, from having been primarily Buddhist structures. Not only the mounds but also the entire site had become imbued with animistic rather than Buddhist beliefs. Most of the stories about the site evolved around animistic beliefs and practices and had to do with phii (spirits). They involved otherworldly and supernatural explanations. Phii was the reason behind the strong hesitation from the residents of the village to participate in the excavations initially. And phii was also the explanation as to why bad things happen to people who remove objects from the site. This is because phii occupy these ruins and are their guardian spirits. Decay had turned the ancient temple foundations into animated objects, and as such, they could remain even though a new temple was to be constructed at the same site. As empowered and magic objects, the ruins help to protect the prestige of the village and its residents (Figure 3). To retain a decayed structure, and just restoring or maintaining its spiritual values through merit-making acts, has nothing to do with its form and fabric. It sustains good relations with ancestral and guardian spirits and gives protection against bad and evil spirits (cf. Tambiah 1970).

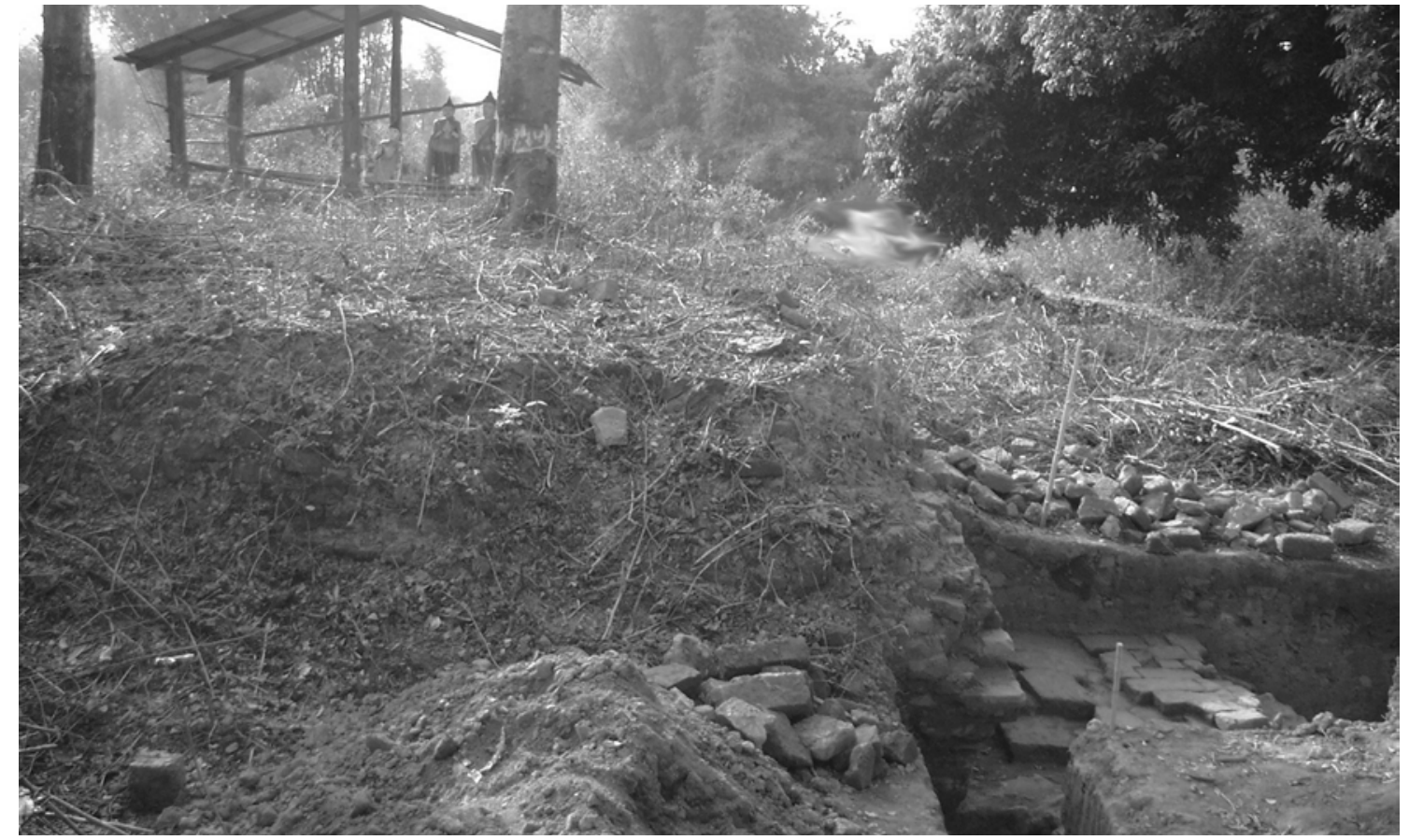

Figure 3. The old temple site in Viengkham, still in use during the excavation in February 2004.

Source: Photo Anna Karlström. 
In conclusion, these three examples illustrate other approaches to destruction and decay than those dominant within contemporary heritage discourse. At Vat Ou Mong, destruction of the old sim was necessary for the spiritual values to be maintained. If the old sim had remained, the spiritual values would have been stuck within it and wasted, not free to enter the new sim. In Phonesay decay was part of the restoration act as the ancient stupa is the instrument through which the significance of Buddha's life reaches people in the present. And in Viengkham, decay has transformed the temple ruins from being Buddhist monuments to being animistic objects containing guardian/protective spirits where spiritual values are conserved through merit-making acts. Accordingly, destruction and decay are sometimes needed for the appreciation of certain heritage expressions.

\section{Consumption, looting and loss}

Consumption is inherently destructive. It involves elimination, the using up of resources and the destruction of material culture itself. A common idea, both within academia and among the general public is that consumption is a threat to society and its spiritual and moral values, that it is a danger to both society and the environment. It is seen in opposition to production, which is associated with creativity and considered the manufacture of value. However, consumption must not only be about buying things or equivalent to modern mass consumption and used as a critique against capitalism. Other approaches have been argued for over the last two decades within, for example, material culture studies. These approaches challenge predominant dichotomies and try to see beyond consumption and destruction as opposed to production and creativity. Instead, they emphasise the relation between consumption and creativity, and consider consumption as a way of developing relationships with things (cf. Miller 2008). Such approaches draw attention to the appreciation of consumption and should be applicable also within the heritage discourse. I would argue that this is necessary if we want to continue working with applied heritage management in Buddhist contexts (and of course elsewhere, but I illustrate it here through my examples from a Buddhist context) as Buddhism encourages spending rather than saving, which is reflected in economic systems examined by Melford E. Spiro in the 1960s. His case study was Burmese, but Buddhist notions are also more generally applicable. He introduces his paper in American Anthropologist as follows:

The Buddhist world view, and especially its notions of rebirth and karma, provide a cognitive orientation within which religious spending is a much sounder and much more profitable investment than economic saving ... (1966:1163)

By spending, and directing the surplus towards merit-making, the spender becomes a consumer. Consequently, in this case and as we can see through the examples above in the previous paragraph, consuming heritage becomes the prerequisite for maintaining its value.

Plundering and looting are needless to say huge problems within the field of archaeology and heritage conservation. It is an issue that has been discussed over the last two decades, often in connection to debates on the ethics of archaeology (cf. Zimmerman, Vitelli and Hollowell 2003; Scarre and Scarre 2006), with focus on subsistence digging (when people dig up artefacts to sell and use the money to support a subsistence lifestyle), the commercial use of artefacts and the illicit nature of looting (cf. Brodie, Doole and Renfrew 2001), and on collecting and archaeological excavation as destructive activities. Different kinds of looting represent different problems and require different approaches. Following a discussion of the diverse moral claims that surrounded subsistence digging among members of the World Archaeology Congress (WAC) in 2003, Julie Hollowell points out that there is a wide variety of positions taken in either justifying or critiquing subsistence digging (2006:73-93). These issues will not be discussed further here. 
What I want to bring up is rather the double function of looting that exists in many contexts (Laos among others); a fact that has almost never been raised in recent debates about looting and the commercial use of artefacts. On one hand, the plundering of an object is illegal. Plundering damages the archaeological record, there is a loss of information about the past and a loss of a heritage that is owned by all of humanity. These arguments are the ones most often heard in the debates, so I will therefore not repeat them. But on the other hand, plundering might be part of the local religious practice and belief, and therefore necessary if we want the traditions and cultures that are based on these beliefs and practices (i.e. certain cultural heritage) to be maintained, and that is what I want to bring up here.

In a Buddhist context, abandonment, decay and impoverishment are continuously balanced against the process of maintenance and restoration as we have seen already. Suddenly a religious structure is considered worn out and in no use for merit-making. What remains then are the sacred objects, objects animated with power through rituals impregnated by Buddhist as well as animist ideas, but free for anyone to plunder. Plunderers are often pious Buddhists, seeking sacred objects to use in their everyday religious life. The plundering could be regarded as a release of the objects, which allows them and their spiritual values to 'pour forth' into the greater world and be of further use, because the object itself holds more value than the fact that it was buried under or placed inside a religious structure (Karlström 2009:208-210). Plunderers would then rather be looked upon as relievers than looters. This is also the case when it comes to the structures themselves, which are considered looted as people remove parts from them. Such cases are the stupas, which are believed to contain fragments of the relics from the historical Buddha's cremation. These are relics that were distributed throughout Southeast Asia along with Buddha's teachings some hundred years after his death. Denis Byrne explains that the 'radiant power of a relic transmits itself to the physical fabric of the stupa encasing it'. Therefore, he says, it is common when a stupa deteriorates that fragments of it are 'taken away to be encased within new stupas, the empowered fabric of the old stupas thus seeding new ones' (2007:159). ${ }^{8}$ Similar occurrences also take place in other parts of the world that are not necessarily Buddhist. In David Matsuda's example from Latin America, he demonstrates how the local people he worked together with regards the unearthed (looted) artefacts as gifts from the ancestors: a 'seed' given by real or mythological patrons to be 'harvested', or excavated, by later generations (1998:87). Another example of a similar situation is Julie Hollowell's experience of working in Alaska. She describes that:

On St Lawrence Island, digging for artefacts is part of every Islander's heritage, an activity that can usually strengthen one's connections with the past. Artefacts are regarded as gifts left by the ancestors that, if they allow themselves to be found, are meant for use in today's world (2006:88).

Within archaeology and heritage discourse today, there is the prevalent view that looting results in a loss of heritage. However, heritage can sometimes be created thanks to loss. One example is the destruction of the Bamiyan Buddha statues in Afghanistan, which caused strong reactions across the world. This was defined as a crime against culture, an unacceptable destruction of cultural heritage. To destroy such symbolically loaded structures, which before the destruction were identified by international organisations as valuable cultural heritage, is certainly a strong action demonstrating a wish for another social order. However, one can also argue that UNESCO's defence against destruction was an equally strong action (Turtinen 2006:43ff). In fact, the destruction in itself was the main argument for appointing the site as World Heritage and for inscribing it on UNESCO's List of World Heritage in Danger. If heritage is about

8 This also explains why it is believed that thousands of stupas in this part of the world now contain such fragments. 
remembering the past and contributes to people's identities, then destruction and consumption of the archaeological record - the loss of heritage - help us remember even better and might strengthen our identities even more. With these examples, it should be obvious that we need a far more broad-minded discussion about lost and/or gained heritage because, today, heritage is being created more rapidly than it is being lost.

\section{Conservation as change}

If we acknowledge conservation as change it helps us to open up for and better understand the altering meanings of restoration-conservation, destruction and decay, and consumption, looting and loss. Owe Ronström finishes his book on heritage politics at a World Heritage site in Sweden by arguing that conservation is change (2007:292):

Preserve or change? What is really what? To preserve something only because it is old is a fairly new idea, and the product of such acts of conservation is always something entirely new. There has always been change, the one thing in the world that does not change. Therefore, the problem is conservation, and not change. And after all - is there any more thorough change than the act of conservation??

If we now recall the story about the demolition of the sim at Vat Ou Mong, we might ask ourselves which approach to heritage conservation would here be the most appropriate. Is it possible to bridge the obvious gap between a sophisticated conservationist sensibility where the Lao cultural patrimony should be preserved, and the perceptions and priorities of the local community where the old sim is laid in ruins, the villagers make merit and by doing so take part in and hand over the intangible and ever-changing heritage of a Buddhist community? If it is possible, how can we then bridge this divide, to best meet as many demands as possible? Or is it desirable to even try? Can the sim be included in the heritage conservation process at all?

These are all difficult questions with no simple or straight answers. I think general alternative strategies for dealing with a heritage that is constantly changing are not easily found. We might be better off trying to debate conservation ethics in a somewhat more respectful way, where a situated, particular and non-essentialist approach is argued. What is needed is imagination and sensitivity, to put heritage conservation into practice in a constructive and intelligent way, so that the people involved recognise their rights in justifying the same values, as they consider important and sacred. A baseline for this approach must be to acknowledge the different worlds we have to deal with and accept that the frames of reference within the contemporary heritage discourse cannot and should not be used unswervingly for other realities, other worlds. If we depart from the things themselves and treat things as meanings, rather than immediately assuming that they signify, represent or stand for something, it might be easier to recognise the systems wherein things get their significance, including our own (cf. Strathern 1990). Following this 'meta' perspective we will then be able to acknowledge that there are different worlds, rather than worldviews. There are different realities, rather than different appearances of reality. Henare, Holbraad and Wastell, following Latour (2002; in Henare et al. 2007:11), conclude this by stating that:

For if cultures render different appearances of reality, it follows that one of them is special and better than all the others, namely the one that best reflects reality. And since science - the search for representations that reflect reality as transparently and faithfully as possible - happens to be a modern Western project, that special culture is, well, ours.

9 My translation from Swedish: 'Bevara eller förändra? Vad är egentligen vad? Att bevara något enbart för att det är gammalt är en tämligen ny idé, och resultatet av sådant bevarande blir alltid något alldeles nytt. Och äldst av allt är förändringen, det enda I världen som inte förändras. Därför är det också bevarandet och inte förändringen som är problemet. Och egentligen - finns det någon mer genomgripande förändring än bevarande?’. 
After acknowledging the existence of different worlds, it would have been easy just to keep to our own and separate it from the other. In the case of Vat Ou Mong, a scenario like that may have resulted in our thinking 'let them destroy their cultural heritage'. But if scholarship, political commitment and sensitivity are one and the same (which I hope we all strive for) we have to engage in our different worlds and realities, and look at the differences and similarities to better understand other frames of reference. Even though there are several ways of approaching the ethics of heritage conservation in different parts of the world, the universalist position taken by the contemporary heritage discourse is dominating. UNESCO and ICOMOS represent this discourse. The World Heritage concept initially challenged the national view of cultural heritage. Now it has accordingly been challenged in the name of local and indigenous interests, and pressing questions have been raised about its meaning and ethical status' (Omland 2006:242). Nevertheless, the concept rests on the fundamental idea that a heritage can be held in common. Even though the contemporary heritage discourse aspires to pluralism, it is not comfortable with the immaterial and spiritual. It is something that is seen as irrational and therefore regarded by the West as pre-modern (Byrne 1993), but still authentic. This fragile, exotic Other runs the risk of disintegration when coming in contact with the West. When UNESCO initiated the Convention for the Safeguarding of Intangible Culture Heritage, to meet the local and indigenous interests, these 'endangered authenticities' (Clifford 1988:5) were expected to adjust themselves to and accept the contemporary heritage discourse. One of the main purposes of the Convention is to safeguard the intangible heritage. Safeguarding here means 'measures aimed at ensuring the viability of the intangible cultural heritage, including the identification, documentation, research, preservation, protection, promotion, enhancement, transmission, particularly through formal and non-formal education, as well as the revitalisation of the various aspects of such heritage' (UNESCO 2003, my emphasis). Even if these endangered authenticities and intangible heritage are taken into consideration and conservation strategies are formulated in consultation with local groups, the fundamental aim and necessity of conservation is, as I have already argued, still unquestioned. The problem here is our privileged position in the Western world to direct and decide the framework. We are interested in alternative histories, but not in alternative heritages (cf. Byrne 1991 and Omland 2006), and definitely not in alternative frameworks and different worlds. Because, We want the Other to remain exotic, to confirm our own identities and stating difference and power, placing the Western culture at the top of the civilisation process. Thus, the intangible heritage as defined and preserved by UNESCO is irrelevant in other contexts than the Western.

\section{Conclusion}

To conclude and answer my own questions above, I would argue that as long as the heritage conservation process only follows the framework of the contemporary heritage discourse and UNESCO's universalist ideology, the sim at Vat Ou Mong should not be included. Within the heritage management framework advocating conservation, the sim in question is considered archaeological, a valuable piece of heritage. In the case of merit-making, the sim is not at all conceived or constructed in this way. The sim might well be included in a heritage management process if another frame of reference is used, a frame of reference found within the Lao context. Then it would most likely be included owing to other reasons than the ones stated above, by UNESCO. It would also be managed in a different way. In one respect, the sim is already included in a heritage management process, but one that is directed by another heritage discourse where destruction and decay does not necessarily contradict construction and conservation, and where it is the prestige and the spiritual values that are restored rather than the physical form and fabric. 
I assume that if we aim at returning something to its previous physical state and material authenticity by not adding new materials, it makes us believe that we do not change it. We simply put things back into their original state. But, by showing that restoration in Laos is presentoriented, that things are added and $d o$ change, I hope to have illustrated that conservation in the contemporary heritage discourse is basically about the same thing. It does not matter if we return something to its previous state or if we turn something into a new state, returning and turning are both active processes resulting in change and that something new and more valuable, material or immaterial, is created. Things are not conserved because they are valuable; it is rather so that they become valuable because they are conserved. We want to preserve the past, but instead we create our own imagination of the past (Edson 2004:339). We want to preserve to prevent loss, but instead we create something new. Heritage is created, destroyed and recreated, and therefore it has been argued that the past is a renewable resource (cf. Holtorf 2001). We must acknowledge the past and the things that remain from the past as renewable resources, as something changeable. Otherwise, it means that we assume what people in the future will appreciate and that they will value things in exactly the same way as we do today. And that, in turn, means a kind of 'future-imperialism', a colonisation of future perceptions.

To me, heritage is therefore always both product and process. It may be something monumental or intangible, or even lost. It may be a conserved structure, where the integrity of the physical object, its form and fabric is preserved: a heritage that is created to maintain authenticity and the feeling for originality. It may be a decayed structure, where new things are added and worn out parts are removed: a heritage that is created to maintain an idea of the prestige of the original. It may be a structure that has been deliberately destructed and lost: a heritage that is created to maintain spiritual values. It may be a new structure: a heritage that is created to maintain the possibility for rebirth. What is common is that heritage is created from our different needs, needs from within both the contemporary heritage discourse and local groups.

\section{References}

Brodie, N., Doole, J. and Renfrew, C. (eds) 2001. Trade in illicit antiquities: The destruction of the world's archaeological heritage. McDonald Institute for Archaeological Research, Cambridge.

Byrne, D. 1991. Western hegemony in archaeological heritage management. History and Anthropology 5:269-276.

Byrne, D. 1993. The past of others: Archaeological heritage management in Thailand and Australia. $\mathrm{PhD}$ thesis, The Australian National University.

Byrne, D. 1995. Buddhist stupa and Thai social practice. World Archaeology 27(2):266-281.

Byrne, D. 2007. Surface collection: Archaeological travels in Southeast Asia. AltaMira Press, Lanham.

Clifford, J. 1988. The predicament of culture. Twentieth-century ethnography, literature, and art. Harvard University Press, Cambridge.

Dolff-Bonekämper, G. 2008. Sites of memory and sites of discord: Historic monuments as a medium for discussing conflict in Europe. In: Fairclough, G., Harrison, R., Schofield, J. and Jameson, Jnr. J.H. (eds), The heritage reader, pp. 134-138. Routledge, London.

Edson, G. 2004. Heritage: Pride or passion, product or service? International Journal of Heritage Studies 10(4):333-348.

González-Ruibal, A. 2008. Time to destroy: An archaeology of supermodernity. Current Anthropology 49(2):247-279. 
Henare, A., Holbraad, M. and Wastell, S. (eds) 2007. Thinking through things: Theorising artifacts ethnographically. Routledge, London.

Holbraad, M. 2007. The power of powder: multiplicity and motion in the divinatory cosmology of Cuban Ifá (or mana, again). In: Henare, A., Holbraad, M. and Wastell, S. (eds), Thinking through things: Theorising artifacts ethnographically, pp. 189-225. Routledge, London.

Hollowell, J. 2006. Moral arguments on subsistence digging. In: Scarre, C. and Scarre, G. (eds), The ethics of archaeology: Philosophical perspectives on archaeological practice, pp. 69-93. Cambridge University Press, Cambridge.

Holt, J.C. 2009. Spirits of the place: Buddhism and Lao religious culture. University of Hawaii Press, Honolulu.

Holtorf, C. 2001. Is the past a non-renewable resource?. In: Layton, R., Stone, P. and Thomas, J. (eds), The destruction and conservation of cultural property, pp. 286-297. Routledge, London.

Holtorf, C. 2006. Can less be more? Heritage in the age of terrorism. Public Archaeology 5:101-109.

Johnson, M. 2001. Renovating Hue (Vietnam): authenticating destruction, reconstructing authenticity. In: Layton, R., Stone, P. and Thomas, J. (eds), The destruction and conservation of cultural property, pp. 75-92. Routledge, London.

Karlström, A. 2005. Spiritual materiality: Heritage preservation in a Buddhist World? Journal of Social Archaeology 5(3):338-355.

Karlström, A. 2009. Preserving impermanence: The creation of heritage in Vientiane, Laos. PhD thesis, Uppsala University.

Karlström, A. In press. Authenticity: rhetorics of preservation and the experience of the original. In: Samuels, K. and Rico, T. (eds), The rhetoric of heritage.

Lahiri, N. 2001. Destruction or conservation? Some aspects of monument policy in British India (1899-1905). In: Layton, R., Stone, P. and Thomas, J. (eds), The destruction and conservation of cultural property, pp. 264-275. Routledge, London.

Matsuda, D. 1998. The ethics of archaeology, subsistence digging, and artifact looting in Latin America: Point, muted counterpoint. International Journal of Cultural Property 7(1):87-97.

Meskell, L. 2002. Negative heritage and past mastering in archaeology. Anthropological Quarterly 75:557-574.

Meskell, L. 2012. The nature of heritage: the new South Africa. Wiley-Blackwell, Hoboken.

Miller, D. 2008, So, what's wrong with consumerism? RSA Summer: 44-47.

Omland, A. 2006. The ethics of the World Heritage concept. In: Scarre, C. and Scarre, G. (eds), The ethics of archaeology: Philosophical perspectives on archaeological practice, pp 242-259. Cambridge University Press, Cambridge.

Potkin, A. 2001. Multimedia and digital imaging in environmental and cultural conservation, Vat Ou Mong peri-demolition archive. Cultivate Understanding Multimedia, Vientiane.

Robinson, R. and Johnson, W.L. 1997. The Buddhist religion: An historical introduction. Wadsworth, London.

Ronström, O. 2007. Kulturarvspolitik: Visby - från sliten småstad till medeltidsikon. Carlsson, Stockholm.

Scarre, C. and Scarre, G. (eds) 2006. The ethics of archaeology: Philosophical perspectives on archaeological practice. Cambridge University Press, Cambridge. 
Shanks, M. and Tilley, C. 1987. Social theory and archaeology. Polity Press, London.

Smith, L. 2006. Uses of heritage. Routledge, London.

Spiro, M.E. 1966. Buddhism and economic action in Burma. American Anthropologist 68(5):1163-1173.

Strathern, M. 1990. Artefacts of history: events and the interpretation of images. In: Siikala, J. (ed.), Culture and History in the Pacific. Finnish Anthropological Society, Helsinki.

Tambiah, S.J. 1970. Buddhism and the spirit cults in north-east Thailand. Cambridge University Press, Cambridge.

Turtinen, J. 2006. Världsarvets villkor. Intressen, förhandlingar och bruk i internationell politik. PhD thesis, Stockholm University.

UNESCO. 2003. Convention for the safeguarding of the intangible cultural heritage. UNESCO, Paris.

Wijesuriya, G. 2001. 'Pious vandals': restoration or destruction in Sri Lanka? In: Layton, R., Stone, P. and Thomas, J. (eds), The destruction and conservation of cultural property, pp. 256-263. Routledge, London.

Zimmerman, L.J., Vitelli, K.D. and Hollowell-Zimmer, J. (eds) 2003. Ethical issues in archaeology. AltaMira Press, Walnut Creek. 